\title{
Kepemimpinan dan Organisasi Pembelajar untuk Membangun Budaya Adaptif Korporasi dalam Merespon Perubahan
}

\author{
Oleh: Abdul Muin \\ Institut Agama Islam Al-Khairat, Pamekasan
}

\begin{abstract}
ABSTRAK
Perubahan merupakan issu utama dalam suatu organisasi, tidak terkecuali pada organisasi korporasi. Tuntutan akan kualitas layanan dari stakeholder selalu menggema dari waktu ke waktu. Organisasi korporasi hendaknya harus mampu merespon dan memenuhi kualitas layanan dimaksud. Dinamika perkembangan dan perubahan menuntut pemimpin dapat mendesain organisasinya menjadi organisasi pembelajar untuk mendorong seluruh anggota/karyawan organisasi menjadi insan pembelajar dengan budaya belajar. Organisasi korporasi tetap akan eksis, dapat memberikan pelayanan sesuai dengan selera dan tuntutan stakeholder. Dengan budaya belajar pula, organisasi korporasi akan semakin terbuka terhadap perubahan dan mudah beradaptasi serta mampu bersaing di arena global. Organisasi korporasi yang kuat adalah organisasi korporasi yang mampu merespon perubahan masa depan yang semakin kompleks. Hal ini mustahil terjadi tanpa di backup oleh kepemimpinan organisasi korporasi yang kuat hanya dapat di desain oleh pemimpin yang kuat/efektif (strong/leader). Pemimpin yang kuat/efektif adalah pemimpin yang senantiasa berikhtiar belajar dan membangun budaya belajar dalam organisasinya.
\end{abstract}

Kata Kunci : Kepemimpinan, Organisasi Pembelajar, Budaya Pembelajar, Perubahan 


\section{Konsep Organisasi Pembelajaran}

Dalam konteks ini pemimpin dapat diharapkan dapat membentuk ulang organisasi korporasinya dalam bentuk baru yang lebih sensitive dan responsive terhadap perubahan yang sering disebut sebagai organisasi pembelajaran (Learning organization). Mengutip pendapat McGill dan Slocum ${ }^{1}$, Safaria Triantoro ${ }^{2}$, mendefinisiskan organisasi menjadi sadar akan kualitas, pola-pola, dan akibat-akibatnya dari pengalamannya sendiri dan mengembangkan model mental untuk memahami pengalaman tersebut. Organisasi pembelajar adalah pola sadar diri, introspektif organisasi yang secara terus-menerus memahami lingkungannya dengan cermat, baik lingkungan internal maupun lingkungan eksternal.

Pada organisasi pembelajaran setiap anggota organisasi korporasi terlibat dalam mengidentifikasikan masalah dan ikut pula memecahkan masalah tersebut dengan solusi yang efektif. Keadaan ini membuat organisasi korporasi secara terus-menerus mampu mencoba, memajukan dan meningkatkan kemampuannya untuk suskes menghadapi persaingan global. Dalam perspektif Organisasi pembelajaran dicirikan sebagai organisasi yang berdasarkan pada kesederajatan, informasi terbuka, sedikit hirarkis, dan sebuah budaya yang dimiliki bersama yang mendorong kemampuan adaptasi dan membuat organisasi mampu untuk menangkap, meraih kesempatan dan menangani krisis secara cepat. Pada organisasi pembelajaran, pemimpin menekankan pemberdayaan karyawan dan mendorong kolaborasi melewati berbagai depertemen dan organisasi. Nilai utama dari organisasi pembelajar adalah pemecahan masalah, berlawanan dengan organisasi tradisional yang dibentuk untuk mencapai kinerja yang efisien. Pemimpin pada organisasi pembelajar membangun keterbukaan komunikasi, pertukaran ide-ide yang kritis, kolaborasi total dari seluruh anggota organisasi, dan stakeholdernya dalam merespon perubahan.

\section{Membangun Kultur Pembelajar pada Organisasi Korporasi}

Chris Argryris menegaskan bahwa ada dua perbedaan proses belajar yang dilaksanakan oleh organisasi. Proses belajar organisasi pertama disebut sebagai

\footnotetext{
${ }^{1}$ DAVID LEI JOHN W. SLOCUM JR, The Tipping Points of Business Strategy: The Rise and Decline of Competitiveness.' Organizational Dynamics, Vol. 38, No. 2, pp. 131-147, 2009'

${ }^{2}$ Safaria Triantoro, Kepemimpinan, Graha Ilmu, 2004
} 
lompatan-tunggal (single loop/first-order) sedang proses belajar yang kedua dikenal sebagai lompatan-rangkap (double loop/second-order). Perbedaan kedua sangat mencolok seperti yang diterangkan dibawah ini. ${ }^{3}$

Lompatan-tunggal (single loop) atau tingkat pertama, proses belajar digunakan untuk meningkatkan kapasitas organisasi untuk mencapai tujuan yang jelas. Prosesnya berhubungan dengan kegiatan yang rutin dan belajar perilaku. Dari proses ini organisasi memperoleh hasil belajar tanpa perubahan yang signifikan di dalam asumsi-asumsi dasarnya.

Lompat-rangkap (double loop), proses belajar dilakukan untuk mengevaluasi-ulang tujuan organisasi termasuk nilai-nilainya serta kepercayaan dasarnya. Tipe belajar ini melibatkan perubahan budaya organisasi. Yang paling penting dari proses belajar ini dalah organisasi belajar untuk bagaimana belajar memperoleh pemahaman yang mendalam tentang dirinya sendiri.

Peter Senge ${ }^{4}$ memberikan karakteristik proses belajar organisasi melalui perspektif teori system. Mereka membedakan dua model belajar organisasi, yaitu pola belajar adaptif (adaptive learning) dan pola belajar generative (generative learning). Pola belajar adaptif merupakan tahap pertama dari proses belajar organisasi dalam beradaptasi terhadap berubahan lingkungan. Belajar adaptif berarti organisasi hanya berfokus pada bagaimana memecahkan masalah, mencapai tujuan organisasi dengan system yang telah ada. Hal-hal yang ditekankan oleh organisasi adalah masalah-masalah yang sifatnya permukaan, bukan masalah-masalah terdalam. Dengan demikian, pola belajar adaptif sama dengan pola belajar lompat-tunggal dari Argyris. Sedangkan pola belajar generative melibatkan kreativitas dan inovasi sehingga tidak saja organisasi mampu mengatasi masalahnya, tetapi mampu mengambil tindakan pencegahan. Organisasi dengan pola belajar generative selalu berusaha mempertanyakan system yang telah ada, apakah masih berfungsi secara efektif bagi organisasi dalam pencapaian kemajuan total. Organisasi menjadi mampu melampaui masalah dengan mengantisipasi perubahan dan secara terusmenerus melakukan pembentukan total pengalaman organisasi dan belajar dari proses tersebut. Organisasi ini menjadikan perubahan bagian dari budayanya sehingga organisasi menganggap perubahan merupakan sesuatu yang alamiah dan memang harus dilakukan.

\footnotetext{
${ }^{3}$ Luthans, F., (1995) Organizational Behavior, Seventh Edition, Singapore: Mc Graw - Hill.

${ }^{4}$ Senge, Peter M. (1994). The Fifth Discipline: The Art and Practice of the Learning Organization, USA New York: Doubleday.
} 
McGill dan Slocum ${ }^{5}$, yang dikutip oleh Triantoro Safaria (2004) dalam bukunya "Kepemimpinan" mengatakan organisasi pembelajar memiliki tujan karakteristik yang membedakannya dengan organisasi tradisional, yaitu:

1. Budaya organisasi mendorong dan mendukung belajar, keterbukaan pada pengalaman dan tanggung jawab terhadap risiko.

2. Organisasi pembelajar mempraktikkan eksperimentasi yang kontinu melalui pembuatan perubahan-perubahan kecil.

3. Organisasi pembelajar mempunyai garis yang fleksibel antara manajemen, pekerja pelanggan dan bahkan pesaingnya. Struktur ditekankan ulang pada hasil yang diinginkan.

4. Anggota organisasi berfokus pada nilai informasi. Informasi ini harus berguna, bukkan diambil karena hal itu menjadi cara lama untuk menyelesaikan sesuatu.

5. System reward organisasi mendorong belajar. Gaji dan promosi dikaitkan pada pengambilan risiko, fleksibelitas, mendorong perbedaan, dan kegagalan tidak secara otomatis dikaitkan pada hukuman.

6. Organisasi memilih calon karyawan berdasarkan kemampuan mereka untuk belajar, dari pada semata-mata menekankan pada pengetahuan apa yang dimilikinya.

7. Peran pemimpin adalah mendorong dan memotivasi belajar, dan berusaha tidak mengikuti pola-pola lama yang sudah tidak efektif lagi.

McGill dan Slocum, ${ }^{6}$ menjelaskan tipe-tipe organisasi yang menunjukkan apakah organisasi tersebut termasuk dalam tipe organisasi pembelajar. Menurut mereka, organisasi dibedakan pada apa filosofi yang dianut oleh organisasi, bagaimana praktik manajemen yang diterapkan, bagaimana pandangan organisasi terhadap karyawannya, bagaimana organisasi memandang pelanggan, dan berkhir bagaimana organisasi memandang perubahan itu sendiri sebagaimana gambar berikut ini:

\footnotetext{
${ }^{5}$ DAVID LEI JOHN W. SLOCUM JR, The Tipping Points of Business Strategy: The Rise and Decline of Competitiveness.' Organizational Dynamics, Vol. 38, No. 2, pp. 131-147, 2009'

${ }^{6}$ ibid
} 


\begin{tabular}{|c|c|c|c|c|}
\hline & Knowing & Understanding & Thingking & Learning \\
\hline Filosofi & $\begin{array}{cl}\text { Dedikasi pada satu cara } \\
\text { terbaik } & \\
- & \text { prediktasi } \\
- & \text { kontrol } \\
- & \text { efesiensi }\end{array}$ & $\begin{array}{l}\text { Dedikasi pada nilai } \\
\text { budaya yang kuat } \\
\text { yang mengarahkan } \\
\text { strategi dan aksi } \\
\text { percaya pada "ruling } \\
\text { myth" }\end{array}$ & $\begin{array}{l}\text { Memandang bisnis } \\
\text { sebagai rangkaian } \\
\text { masalah, jika rusak } \\
\text { perbaiki } \\
\text { secepatnya }\end{array}$ & $\begin{array}{l}\text { Menguji } \\
\text { meningkatkan dan } \\
\text { memajukan setiap } \\
\text { pengalaman } \\
\text { bisnis, termasuk } \\
\text { bagaimana kita } \\
\text { mengalaminya }\end{array}$ \\
\hline $\begin{array}{l}\text { Praktik } \\
\text { manajemen }\end{array}$ & $\begin{array}{l}\text { Mempertahankan } \\
\text { kontrol melalui } \\
\text { peraturan dan kebijakan } \\
\text { yang tertulis }\end{array}$ & $\begin{array}{l}\text { Mengklarifikasikan } \\
\text { mengkomunikasikan } \\
\text { menguatkan budaya } \\
\text { organisasi }\end{array}$ & $\begin{array}{l}\text { Mengidentifikasik } \\
\text { an dan mengisolasi } \\
\text { masalah, } \\
\text { mengumpulkan } \\
\text { data, menerapkan } \\
\text { solusi }\end{array}$ & $\begin{array}{l}\text { Mendorong } \\
\text { eksperimentasi, } \\
\text { memfasilitasi } \\
\text { pengujian, } \\
\text { mempromosikan } \\
\text { perbedaan } \\
\text { pendapat, } \\
\text { menghargai } \\
\text { kegagalan }\end{array}$ \\
\hline Karyawan & $\begin{array}{l}\text { Harus mengikuti aturan, } \\
\text { jangan bertanya } \\
\text { mengapa }\end{array}$ & $\begin{array}{l}\text { Menggunakan nilai } \\
\text { corporat sebagai } \\
\text { pedoman } \\
\text { berperilaku }\end{array}$ & $\begin{array}{l}\text { Merangkul } \\
\text { antusiasme } \\
\text { mennjalankan } \\
\text { program } \\
\text { pemecahan } \\
\text { masalah } \\
\end{array}$ & $\begin{array}{l}\text { Memperoleh dan } \\
\text { mempergunakan } \\
\text { informasi serta } \\
\text { secara konstruktif } \\
\text { memperdebatkann } \\
\text { ya }\end{array}$ \\
\hline Pelanggan & $\begin{array}{l}\text { Harus percaya bahwa } \\
\text { perusahaan yang paling } \\
\text { tahu segalanya }\end{array}$ & $\begin{array}{l}\text { Meyakinkan nilai- } \\
\text { nilai perusahaan, } \\
\text { memastikan } \\
\text { penngalaman positif }\end{array}$ & $\begin{array}{l}\text { Mempertimbangka } \\
\mathrm{n} \text { masalah untuk } \\
\text { dipecahkan }\end{array}$ & $\begin{array}{l}\text { Bagian dari proses } \\
\text { belajar-mengajar, } \\
\text { dengan } \\
\text { keterbukaan dan } \\
\text { dialog yang } \\
\text { kontinu }\end{array}$ \\
\hline perubahan & $\begin{array}{ll}\text { Bersifat } & \text { inkrimental } \\
\text { harus } & \text { dicocokkan } \\
\text { dengan cara } & \text { terbaik }\end{array}$ & $\begin{array}{l}\text { Hanya di dalam } \\
\text { "ruling myth" }\end{array}$ & $\begin{array}{l}\text { Diimplementasika } \\
\mathrm{n} \text { melalui program } \\
\text { pemecahan } \\
\text { masalah, yang } \\
\text { dianggap sebagai } \\
\text { obat } \\
\text { penyembuhannya }\end{array}$ & $\begin{array}{l}\text { Bagian dari proses } \\
\text { berkesinambunga } \\
\mathrm{n} \text { dari pengalaman } \\
\text { hipotesis- } \\
\text { pengujian } \\
\text { pengalaman }\end{array}$ \\
\hline $\begin{array}{l}\text { Contoh } \\
\text { organisasi } \\
\text { nyata }\end{array}$ & $\begin{array}{l}\text { Walt Disney, UPS Avis, } \\
\text { McDonald Blocbuster } \\
\text { Vidio }\end{array}$ & $\begin{array}{l}\text { IBM, Apple, P\&G, } \\
\text { Sears, } \quad \text { General } \\
\text { Motor Johson \& } \\
\text { Johnson }\end{array}$ & $\begin{array}{l}\text { Foley Departemen } \\
\text { Store }\end{array}$ & $\begin{array}{l}\text { Home } \text { Depot } \\
\text { Sony, 3M, Honda } \\
\text { Walt Mart, Levi } \\
\text { Strauss }\end{array}$ \\
\hline
\end{tabular}

Peter Senge ${ }^{7}$ juga mencoba untuk membedakan antara organisasi tradisional dengan organisasi pembelajar. Menurutnya ada perbedaan yang mencolok anatara organisasi tradisional dengan organisasi pembelajar yang dilihat dari arah keseluruhan organisasi, formulasi dan implementasi ide, cara berpikir organisasi, pemecahan konflik, kepemimpinan, dan motivasi. Untik lebih jelasnya dapat dilihat pada gambar dibawah ini:

\footnotetext{
${ }^{7}$ Senge, Peter M. (1994). The Fifth Discipline: The Art and Practice of the Learning Organization, USA New York: Doubleday.
} 


\begin{tabular}{|c|c|c|}
\hline Fungsi & Organisasi Tradisional & Organisasi Pembelajar \\
\hline $\begin{array}{l}\text { Penentu arah } \\
\text { keseluruhan }\end{array}$ & Visi diberikan oleh manajemen puncak & $\begin{array}{l}\text { Adanya sebuah visi bersama (shared } \\
\text { vision) }\end{array}$ \\
\hline $\begin{array}{l}\text { organisasi } \\
\text { Formulasi dan } \\
\text { Implementasi } \\
\text { ide-ide }\end{array}$ & $\begin{array}{l}\text { Manajemen puncak memutuskan apa yang } \\
\text { harus diselesaikan, dan yang lainnya harus } \\
\text { mengikutinya }\end{array}$ & \\
\hline $\begin{array}{l}\text { Cara berpikir } \\
\text { organisasi }\end{array}$ & $\begin{array}{l}\text { Setiap orang bertanggung jawab atas tugas- } \\
\text { tugasnya sendiri, dan menekankan pada } \\
\text { peningkatan kompetensi individual }\end{array}$ & $\begin{array}{l}\text { Karyawan memahami tugas-tugasnya } \\
\text { sebagaimana memahami dengan baik } \\
\text { hubungannya dengan tugas-tugas } \\
\text { karyawan lainnya. }\end{array}$ \\
\hline $\begin{array}{l}\text { Penanganan } \\
\text { konflik }\end{array}$ & $\begin{array}{l}\text { Konflik dipecahkan melalui penggunaan } \\
\text { kekuasaan dan pengaruh hirarkis }\end{array}$ & $\begin{array}{l}\text { Konflik dipecahkan melalui proses } \\
\text { belajar kolaboratif, dan penyatuan } \\
\text { berbagai macam pandangan-pandangan } \\
\text { karyawan di seluruh organisasi }\end{array}$ \\
\hline $\begin{array}{l}\text { Kepemimpinan } \\
\text { dan motivasi }\end{array}$ & $\begin{array}{l}\text { Peran pemimpin adalah menciptakan visi } \\
\text { organisasi, memberikan hadia dan } \\
\text { hukuman secara tepat, dan } \\
\text { mempertahankan kontrol pada seluruh } \\
\text { aktivitas bawahan }\end{array}$ & $\begin{array}{l}\text { Peran pemimpin adalah membangun } \\
\text { visi bersama, memberdayakan, } \\
\text { mengilhami komitmen, mendorong } \\
\text { pengambilan keputusan efektif pada } \\
\text { seluruh organisasi, melalui } \\
\text { pemberdayaan dan kepemimpinan } \\
\text { kharismatik }\end{array}$ \\
\hline
\end{tabular}

\section{Kultur Korporasi dalam Organisasi Pembelajaran}

Pada organisasi pembelajar budaya menjadi dangat adaptif, sehingga mampu mengahadapi perubahan dan tuntutan globalisasi. Banyak organisasi yang tadinya sangat sukses, secara perlahan-lahan mulai mengalami kemunduran. Hal ini diakkibatkan karena budaya-budaya baru yang sebenarnya lebih adaptif. Pada organisasi pembelajar, budaya tidak menjadi kaku, tetapi senantiasa dievaluasi apakah masih mampu menjawab tantangan zaman. Jika budaya organissi dianggap sudah tidak adaptif lagi, maka perubahan baru akan dilakukan, hal ini membuat organisasi pembelajar selalu dapat menyesuaikan diri dengan perubahan-perubahan yang cepat karena fleksibelitasnya dana keyakinannya akan pentingnya perubahan bagi organisasi.

Selanjutnya Daft, ${ }^{8}$ mengatakan bahwa budaya organisasi pembelajar dicirikan sebagai berikut:

a. Keseluruhan lebih penting dari bagian-bagian dan pembatasan antara bagian diminimalisasikan (the whole is more important than the part and boundaries between parts are minimized). Anggota organisasi sadar akan keseluruhan system,

\footnotetext{
${ }^{8}$ Daft, Richard L. 1992. Organization Theory and Design. Fourth edition. Singapore: West Publishing Company.
} 
bagaimana semua tergantung satu dengan lainnya, dan sadar akan hubungan diantara beragam bagian organisasi. Setiap orang mempertimbangkan bagaimana tindakan mereka mempengaruhi elemen lain organisasi. Pembatasan selalu dikurangi, aliran ide, informasi, dan orang-orang menciptakan aksi yang terkoordinasi dan munculnya proses belajar yang terus-menerus.

b. Kesederajatan adalah nilai utamanya (equality is a primary value). Budaya dari organisasi pembelajar menciptakan sebuah rasa kebersamaan, kasih sayang, dan perhatian satu dengan lainnya. Setiap orang sangat dihargai keberdaannya, dan organisasi menjadi tempat untuk menjalin relasi yang manusiawi, serta mendorong anggota untuk mengembangkan potensi mereka secara penuh.

c. Budaya organisasi mendorong perubahan, pengambilan risiko dan pemberdayaan (the culture encourages change, risk-taking, and improvement). Nilai dasar organisasi pembelajar adalah selalu menolak status quo, dan senantiasa mengevaluasi setiap kegiatan dan tindakan yang dilakukannya. Secara terbuka segala hal yang dipertanyakan, dan organisasi sangat menghargai ide-ide baru, produk baru, dan proses kerja baru. Organisasi juga menghargai kegagalan sebagai bagian dari keberanian mengambil risiko, tujuannya adalah agar karyawan mampu belajar dari kegagalan.

Tantangan yang dihadapi pemimpin saat ini sangatlah berat. Di satu sisi di dituntut untuk mempertahankan kinerja yang efisien dan di sisi lain dituntut untuk menjadikan organisasinya menjadi organisasi pembelajar. Pemimpin harus mampu menjaga keseimbangan antara sisi keras organisasi dan sisi lembut organisasi. Pemimpin dituntut untuk meminimalisir batasan yang terlalu kaku, sehingga menyebabkan kesenjangan yang besar antara satu departemen dengan departemen lainnya. 


\section{Paradigma Pemimpin Korporasi Pada Organisasi}

\section{Pembelajaran}

Istilah "paradigma" diartikan sebagai cara pandang atau perspektif bagaimana seorang pemimpin melihat dunianya. Cara pandang pemimpin dalam memahami dunia sangat mempengaruhi keputusannya dan bagaimana dia bertindak di dalam organisasi. Pemimpin yang memiliki perspektif yang sempit cenderung terjebak dalam sudut pandang yang memenjarakan diri sendiri, membuatnya tidak mampu melihat masalah dengan wawasan yang lebih luas. Akibatnya, pemimpin menjadi kurang efektif dalam pengambilan keputusan dan pemecahan masalah. Jika pemimpin hanya memusatkan perhatian pada satu perspektif semata, maka organisasi yang dipimpinnya akan sulit untuk berkembang secara cepat dan beradaptasi dengan efektif terhadap perubahan global.

Pemimpin masa depan dituntut untuk mampu melihat masalah dari berbagai perspektif, agar pemecahan yang dibuatnya menjadi efektif dan bersifat menyeluruh. Perspektif yang luas tidak saja akan membantu pemimpin di dalam memecahkan masalah, tetapi juga akan membuat pemimpin tajam dalam mengevaluasi setiap kejadian yang akan mempengaruhi organisasinya. Karena paradigma yang dimiliki pemimpin akan sangat mempengaruhi persepsinya, penilaiannya, sikapnya, dan perilakunya dalam mengendalikan organisasi.

Gambar dibawah ini menjelaskan empat paradigma yang dimiliki pemimpin dalam memahami dunianya. Dibawah ini akan dijelaskan satu persatu dari keempat paradigma tersebut ${ }^{9}$.

\footnotetext{
${ }^{9}$ Safaria, Triantoro; bin Othman, Ahmad; Wahab, Muhammad Nubli Abdul, The Role of Leadership Practices on Job Stress among Malay Academic Staff: A Structural Equation Modeling Analysis International Education Studies, v4 n1 p90-100 Feb 2011
} 


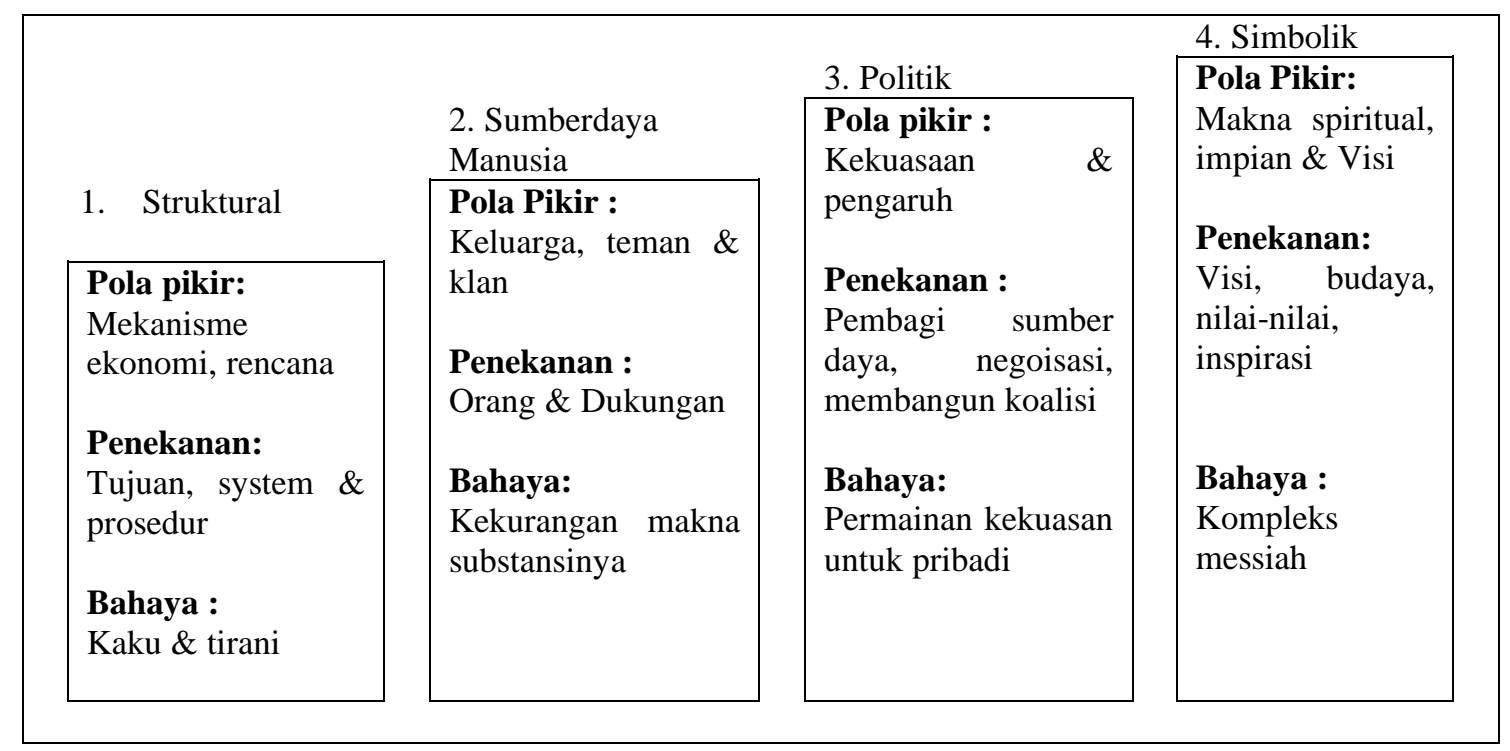

1. Paradigma structural. Pemimpin yang berfokus paradigma atau kerangka pemikiran strukturak ini akan melihat organisasi sebagai mesin yang menuntut efisiensi, dan membuat keputusan berdasarkan efisiensi ekonomik. Perencanaan dan penetapan tujuuan merupakan alat utama manajemen. Pemimpin melihat organisasi dengan menggunakan system rasional, mengklarifikasikan tugas-tugas secara mendetail. Pemimpin menuntut adanya deskripsi pekerjaan yang jelas, kebijakan dan prosedur spesifik dalam kegiatan kerja, semua ini untuk menyediakan keteraturan, efisiensi dan kontinuitas kinerja. Pemimpin lebih menghargai data mentah, angka-angka dan statistic, berfokus pada proses bottom line, dan tidak mentoleransi pelanggaran terhadap pereturan yang ada. Konformitas, kepatuhan, dan pemahaman akan tujuan organisasi sangat ditetaknkan oleh pemimpin. Bahaya yang muncul dari paradigma structural ini adalah budaya organisasi yang kaku, senetralissi yang kuat, muncul tirani, dan pemimpin yang otoriter.

2. Paradigma sumber daya manusia. Pemimpin yang lebih berpegang pada kerangka berpikir sumber daya manusia menegaskan bahwa manusia merupakan sumber daya organisasi yang paling berharga. Pemimpin lebih banyak berusaha menyesuaikan system yang ada diorganisasinya agar sesuai dengan kekbutuhan manusia atau anggotanya. Pemimpin menghargai hubungan manusiawi, perasaan dan memimpin melalui pemberdayaan dan dukungan. Pemimpin jenis ini mendorong terciptanya iklim komunikasi yang terbuka, tim-tim kerja dan partisipasi penuh. Pemimpin 
memberikan kesempatan untuk mengemlibangkan pribadi dan professionalitas bawahannya, dengan memberikan ruang terbuka bagi bawahan untuk berdialog, mau membantu bawahannya dan mau melayani mereka. Pemimpin memandang organisasi sebagai suatu masyarakat atau klan-klan yang saling menghargai satu dengan lainnya. Bahaya yang mungkin muncul adalah pemimpin menjadi terlalu manusiawi sehingga tidak berani untuk memaksa kinerja yang lebih tinggi, sehingga kekurangan makna terdalam dari kepemimpinan.

3. Paradigma politik. Pemimpin yang mempunyai kerangka berpikir politik memandang organisasi sebagai tempat perebutan kekuasaan yang secara terusmenerus memicu konflik yang memperebutkan sumber daya yang tersebar di organnisasi. Pemimpin jenis ini senantiasa membangun jaringan kerja, dan koalisi kekuasan untuk mempengaruhi keputusan hal yang positif dari pemimpin adalah kemampuannya dalam membangun koalisi, mampu melakukan negoisasi, dan kemampuannya menyatukan seluruh anggota organisasi dalam satu visi agar kebutuhan organisasi terpenuhi. Pemimpin memandang organisasi seperti hhutan yang lebat, kekuasaan adalah kenyataan, dan untuk itu dia harus menyiapkan seluruh tenaganya untuk menguasai organisasi sepenuhnya. Bahaya yang mungkin muncul dari pemimpin ini adalah munculnya penipuan, kebohongan public dan bermain politik untuk kepentinggan diri sendiri.

4. Paradigma simbolik. Pemimpin yang mempunyai kerangka berfikir simbolik melihat dunia yang kacau sebagai suatu makna tersendiri, fakta -fakta yang harus diinterpretasikan dan bukan diterima sebagai sesuatu yang semata-mata objektif. Pemimpin memandang organisasi sebagai sebuah system makna bersama yang penuh dengan nilai-nilai yang harus dipenuhi. Pemimpin menggunakan ritual, perayaan, cerita-cerita dan simbol-simbol lainnya untuk menciptakan dan menegaskan sebuah budaya corporat. Pemimpin simbolik berfokus pada visi bersama, budaya dan nilai-nilai dalam memimpin organisasi dan secara terusmenerus memberikan inspirasi bawahan agar mencapai tingkat tertinggi dalam kinerja dan komitmennya terhadap organisasi. Bahaya yang mungkin muncul adalah pemimpin yang mengalami kompleks messiah seperti seorang nabi yang memberikan pencerahan pada organisasi, sehingga pemimpin pada akhirnya hanya mementingkan dirinya sendiri dibandingkan dengan organisasi atau karyawannya. 
Pemimpin bias menggunakan symbol-simbol untuk memenangkan dan menyebarkan pandangannya agar orang lain mengikutinya tanpa pertanyaan kritis.

Bagaimana pemimpin seharusnya memusatkan kerangka berpikirnya bagi organisasi pembelajar? Untuk mampu dengan baik membawa organisasinya menjadi organisasi pembelajar pemimpin harus mampu menggunakan keempat paradigma di atas secara seimbang. Pemimpin dapat menggunakan keempat paradigma di atas dengan melihat situasi dan kondisi yang sedang dihadapi oleh organisasinya. Ketika organisasinya membutuhkan pemenuhan akan makna maka pemimpin lebih berfokus pada paradigma simbolik. Tetapi ketika pemimpin melihat bahwa organisasinya mulai mengalami perpecahan, dia dapat berfokus pada paradigma politik untuk bagaimana membangun koalisi dan mencapai rekonsiliasi dalam organisasi.

Dengan pemimpin mengembangkan keempat perspektif di atas maka pemimpin akan lebih efektif di dalam mengatasi masalah yang sedang di hadapi oleh organisasi. Keterbukaan wawasan yang sedang di hadapi oleh organisasi. Keterbukaan wawasan dari pemimpin akan mendorongnya untuk lebih efektif di dalam membawa organisasinya menuju abad XXI. Sebaliknya, jika pemimpin hanya berfokus pada satu perspektif saja, maka kemampuan pemimpin di dalam memecahkan masalah menjadi kurang efektif, pemahamannya akan terlalu sempit dan organisasi bisa mengalami kemunduran yang nyata. 


\section{Kesimpulan}

Pertama, Budaya belajar yg dibangun dalam perspektif Learning Organization yakni "generative learning" agar setiap anggota/karyawan dalam korporasi bertindak kreatif dan inovatif dalam menghadapi tantangan dan mampu merespon perubahan. Kedua, Kultur yg dibangun dalam suatu organisasi/korporasi dalam perspektif learning organization yakni: (a) Keseluruhan lebih penting dari bagian-bagian; (b) Kesederajatan dan (c) Mendorong perubahan, pengambilan risiko, dan pemberdayaan. Kedua, Dengan learning organization dapat mendorong seorang leader dituntut untuk mampu melihat problem dari berbagai sudut pandang/perspektif agar proses penyelesaiannya lebih efektif dan komprehensif disamping itu juga dapat mensupport pemimpin untuk mampu melakukan evaluasi secara menyeluruh setiap kebijakan yg telah ditetapkan 


\section{Daftar Pustaka}

Bennis Warren, On Becoming a Lead, Wesley Publishing Company, 1989.

Cook, Marshall J, How to Be a Great Coach (terjemah Paul Alfried Rajoe), Pt Bhuana Ilmu Populer, Jakarta, 2004.

Danim, Sudarwan, Visi Baru Manajemen Sekolah Dari Unit Birikrasi ke Lembaga Akademik, PT Bumi Aksara, Jakarta, 2007.

Danim, Sudarwan, Kepemimpinan Transformasional Dalam Komunitas Organisasi Pembelajaran, PT Bumi Aksara, Jakarta, 2003.

Fundation Druker, A Leader to Leader Guide, Drucker Fundation, New York.

Gary Yulk, Kepemimpinan Dalam Organisasi, Jakarta: Victory Jaya Abadi, 1994.

Gazpers Vincent, TQM, Gramedia Pustaka Utama, Jakarta, 2002

Indrawijaya Adan I, Perubahan dan Pengembangan Organisasi, Sinar Baru Bandung, 1989.

Indrafachrudi Soekarto, Bagaimana Memimpin Sekolah Yang Efektif, Ghalia Indonesia, 1996.

Johnson Spenccer, Who Moverd May Cheese? (Terjemag Juni Prakoso) Elex Media Komputindo, 2002.

Kamariah Aan, Triatna Cepi, Visionary Leadership, Bumi Aksara, Bandung, 2006.

Kartono Kartini, Pemimpin dan Kepemimpinan, Raja Grafindo Persada, 2006.

Keith Davus \& JhonW. Newstrom, Perilaku Dalam Organisasi, Jakarta : Erlangga, 1985.

Mangku Negara Prabu, Perilaku dan Budaya Organisasi, Refika Aditama, Bandung, 2005.

Maxwell John, Developing the Leader Within You (Terjemag Anton Adiwiyoto), Binarupa Aksara, 1995.

Maxwell John C, The Right to Lead (Terjemah Meiliana Purnama), Mitra Media, 2002.

McKenna Regis, The Regis Touch New Marketing Strategis For Uncertain Times, Wesley Publishing Company, 1985.

Mulyasa, Menjadi Kepala Sekolah Profesional, Remaja Rosda Karya, Bandung, 2005. 
Paul Hersey and Blanchard Ken, Manajemen Perilaku Organisasi; Pendayagunaan Sumberdaya Manusia, (Terjemah Agus Dharma), Gelora Aksara Pratama, 1982.

Robbins Stephen P, Teori Organisasi Struktur, Desain dan Aplikasi (Terjemah Yusuf Udaya) Arcon, 1994.

Robert B. Maddux,team Building, Terampil Membangun Tim Yang Gandal, Jakarta; Erlangga, 2002.

Robin Sharma, Leadersip Wisdom, Harper Collins Publisher, Ltd. Toronto, Canada.

Safaria Triantoro, Kepemimpinan, Graha Ilmu, 2004.

Said Mas'ud, Kepemimpinan, UIN Malang Press, 2007.

Siagian Sondang P., Manajemen Abad 21, Bumi Aksara, 2000.

Siagian Sondang P., Teori dan Praktik Kepemimpinan, Rineka Cipta, 1999.

Stephen Robbins, Perilaku Organisasi, Jakarta: PT. Bhuana Ilmu Populer, 1996.

Syafaruddin, Manajemen Mutu Terpadu dalam Pendidikan, Grasindo, 2005.

The Drucher Foundation, a Leader to Leader Guid, (Terjemah Michael Elvin Setiadi), Elex Media Komputindo, 2005.

Thoha Miftah, Kepemimpinan Dalam Manajemen, Raja Grafindo Persada, Jakarta, 1983.

Tobroni, The Spiritual Leadership, Universitas Muhammadiyah Malang, Malang, 2005. 